\title{
Stock Return Predictability: The Role of Inflation and Threshold Dynamics
}

\author{
David G. McMillan \\ Accounting and Finance Division \\ Stirling Management School \\ University of Stirling
}

January 2016

Revised June 2016

This Version September 2016

Accepted for publication in International Review of Applied Economics by Taylor and Francis.

\begin{abstract}
This paper argues that the nature of stock return predictability varies with the level of inflation. We contend that the nature of relations between economic variables and returns differs according to the level of inflation, due to different economic risk implications. An increase in low level inflation may signal improving economic conditions and lower expected returns, while the opposite is true with an equal rise in high level inflation. Linear estimation provides contradictory coefficient values, which we argue arises from mixing coefficient values across regimes. We test for and estimate threshold models with inflation and the term structure as the threshold variable. These models reveal a change in either the sign or magnitude of the parameter values across the regimes such that the relation between stock returns and economic variables is not constant. Measures of in-sample fit and a forecast exercise support the threshold models. They produce a higher adjusted R-squared, lower MAE and RMSE and higher trading related measures. These results help explain the lack of consistent empirical evidence in favour of stock return predictability and should be of interest to those engaged in stock market modelling as well as trading and portfolio management.
\end{abstract}

Keywords: Stock Returns, Predictability, Inflation, Threshold, Forecasting JEL: C22, G12

Address for Correspondence: Professor David McMillan, Accounting and Finance Division, Stirling Management School, University of Stirling, FK9 4LA, Scotland, UK

Phone: +44(0)1786-467309; Fax: +44(0)1786-467308

e-mail: david.mcmillan@stir.ac.uk 


\section{Introduction.}

We consider whether stock return predictability varies over regimes of behaviour that depend on the level of inflation. While existing results in favour of stock market predictability are mixed, there remains an overriding belief that returns should be linked to economic factors. Notably, stock returns are believed to vary with perceptions of risk and thus market-level predictability should be evident in arising from key macroeconomic variables including economic growth, interest rates and inflation. The argument we present in this paper is that the current state of mixed evidence arises because the relation between economic risk and returns is non-linear but the vast majority of the predictability is couched in linear terms. In this paper we examine how predictability varies over different values of inflation. While high inflation is believed to be consistent with high economic risk and so can lead to high stock returns as compensation, we also argue that low inflation has the potential to be equally consistent with high risk and high stock returns as it signal poor economic growth prospects.

The literature on stock return predictability is vast but mixed. Examples of this include, among many, Campbell and Shiller (1988), Fama and French (1988), Goyal and Welsh (2003), Ang and Bekaert (2007), Campbell and Thompson (2008), Cochrane (2008), Kellard et al (2010), Park (2010), McMillan and Wohar (2013), Narayan and Bannigidadmath (2015), Phan et al (2015) and Bannagadadmath and Narayan (2016). Within this literature there is a significant subset that examines the ability of predictability to vary across regimes of behaviour, including explicit non-linear models. Such models tend to find greater evidence of predictability. Key examples of this include Pesaran and Timmermann $(1995,2000)$ who estimate linear models but do so recursively so that at each step any particular regressor may be included or excluded and thus allowing for different regimes of predictability. In a related vein, Campbell and Yogo (2006), Park (2010), Engsted and Pederson (2010) and McMillan (2014) argue the predictability appears over different time 
periods. Further to this, more explicit non-linear models have also been proposed and found to exhibit significant predictive power, examples include McMillan (2003), Psaradakis et al (2004), McMillan and Wohar (2010), while Guidolin et al (2009) present a comprehensive evaluation of non-linear forecasting performance. We believe that the mixed nature of the existing results arises due to the fact that predictability is governed by a non-linear process, such that linear estimation is a mix of regimes and will inevitably produce differing results over differing sample periods. ${ }^{1}$

We argue that the mixed nature of the predictive power noted above and the success of non-linear or models that identify regimes of behaviour occurs because the relation between economic risk and stock returns is not linear. At the most basic level, an expanding economy would be associated with lower economic risk, while a contracting economy is consistent with higher economic risk. Indeed, this view motivates the work of Henkel et al (2011) who argue that counter-cyclical risk premiums lead to evidence of stock return predictability only within recessionary periods. Here, we argue that an expanding economy is associated with higher inflation and higher interest rates, which suggest an increase in economic risk and the possibility of higher returns to compensate. Equally, lower inflation and interest rates may suggest improving expected future economic conditions and lower stock returns. But, very low inflation and interest rates may suggest poor economic expectations and again higher stock returns to compensate for the increased risk. Given this, an equal rise in inflation from a low or high starting point reveals different economic conditions and would have a different impact on stock returns. Therefore, it is important to account for such potential non-linearity in modelling stock return predictability.

In attempting to model this non-linear effect, we believe inflation offers the best choice. Both high and (very) low inflation can be associated with poor economic prospects

\footnotetext{
1 An alternative approach taken in the literature is to use panel analysis to examine predictability, see, for example, Hjalmarsson (2010), McMillan and Wohar (2013) and Westerlund et al (2015).
} 
and high economic risk. The literature linking stock returns and inflation is a large one but we can present a flavour of the differences within it regarding the direction of the relation between stock returns and inflation. Fama (1981) advocates a negative relation through the proxy hypothesis. Here, high inflation is associated with low expected future economic activity and high stock returns are associated with strong expected future economic activity. Therefore, inflation and stock returns move apart given their differing relations with expected future economic conditions. A negative relation is also supported by Fama and Schwert (1977). In contrast, a positive relation has been identified by several authors. Fisher (1930) argues that there exists a positive relation between inflation and the nominal return in order to ensure the real return is held constant. Bodie (1976) suggests an inflation hedge argument, where investors are compensated for higher inflation through higher stock returns, again so that their claim on real assets is unaffected. ${ }^{2}$ Furthermore, an increase in (expected future) inflation (and interest rates) will lead to poorer future economic performance. This in turn will lead to lower current stock prices and higher future stock returns through a higher risk premium and thus a positive relation. Indeed, Sellin (2001) argues that the expectation of a future tightening of monetary policy will lead to higher stock returns (lower prices) now. Moreover, where higher interest rates depress economic activity then this will lead to further downward pressure on stock prices. ${ }^{3}$

A related, but separate point, arises in the literature examining the relation between equity and bond returns and the role of inflation. Our expectation is for a positive correlation between these two assets and particularly during periods of high inflation, which reduces the price of both assets due to higher (expected) interest rates. However, some research argues that at lower levels of inflation and bond yields a negative relation arises. Lower inflation and interest rates lead to higher bond prices but can signal lower equity prices if economic

\footnotetext{
${ }^{2}$ The inflation hedge argument is also made at the firm-level by Bampinas and Panagiotidis (2016).

3 See also, for example, Hansen and Stein (2012) and Gertler and Karadi (2013) for a discussion of how monetary policy can operate through the expected risk premium on stocks.
} 
prospects are poor (Shiller and Beltratti, 1993; Ilamnen, 2003; Eggertsson et al., 2012). The overall conclusion from the above sets of literature is that the effect of inflation on stock returns is not linear and the impact of inflation on economic risk and thus expected returns varies with its level.

We proceed by examining the degree of predictive power for stock returns using a range of variables commonly considered within the literature. After considering a linear regression approach, we test for and estimate a non-linear model, whose regimes depend upon the level of inflation. It is hoped that the results presented here will be use to market participants in aiding portfolio and risk management and market timing and to academics and policy-makers in understanding movements in the stock market.

\section{Data Choice and Motivation.}

The recent work examining stock return predictability literature largely began with Campbell and Shiller (1998) and Fama and French (1988) who argue that the dividend-price ratio acts as a proxy for expected returns and varies with changes in the expected risk premium. As such, an increase in economic risk, will lead to a fall in current prices and a compensatory rise in (expected) future returns. This, therefore, generates a positive relation between the

ratio and returns. In common with the dividend-price ratio (DP), we also include the cyclically-adjusted price-earnings ratio (CAPE, Campbell and Shiller, 1988). This measure applies the same logic as the relation between the DP ratio and stock returns. Here, a high ratio (high stock price) will indicate low future (expected) returns. We also consider the dividend-earnings (or payout) ratio (DE, Lamont, 1998). While the above two ratios focus on the nature of the risk premium, an increase in dividends will also predict higher future returns. The DE ratio furthers this argument, supporting the view that higher dividends predict higher future returns, while also saying that higher earnings predict higher current 
prices (due to lower risk) and thus lower future returns. Thus, the nature of the relation with stock returns depends on the relative effect of changes in dividends and earnings.

In addition to these ratios, we also consider a set of macroeconomic variables. In particular, we consider two interest rates series (the change in the Federal Funds rate and the 10-year to 3-month government bond term structure), a measure of output, inflation and the money supply. Following, for example, Thorbecke (1997), Rigobon and Sack (2004), Bernanke and Kuttner (2005) and Maio (2014) there is believed to be a negative relation between changes in the Federal funds rate and stock returns. Regarding the term structure, an increase in its value is consistent with higher expected future inflation and a monetary tightening. This will lead to a fall in expected future earnings and stock prices. In a similar vein, an increase in the money supply is expected to lead to improved future economic conditions, a higher stock price and lower (expected) future returns. However, it can be argued that knowledge of a higher money supply will lead to higher future inflation, interest rates and economic risk and so higher expected returns (e.g., Sellin, 2001). An increase in output will be consistent with higher stock prices and falling economic risk and so lower expected returns. With regard to inflation, as discussed above, the direction of the relation is unknown with theoretical motivation for both a positive and negative relation.

Turning to a consideration of why the strength of the relations with stock returns may vary with inflation, a high level of (expected) inflation indicates a high degree of economic risk, with the expectation of rising interest rates and a future economic contraction. This higher expected risk should be accompanied with higher (expected) stock returns and a lower stock price. As argued above, where financial ratios (e.g., dividend-price ratio) proxy for expected returns, we would expect enhanced predictive power when such risk is high. Indeed Henkel et al (2011) argue that risk premiums are counter-cyclical and that evidence of predictability only arises during economic downturns. Expanding on this, we argue that 
predictability increases when economic risk is high but does not necessarily disappear during expansionary periods. In a similar vein, Sharpe (2001) argues that low inflation is indicative of a more stable economic environment, which in turn would lead to higher (expected) earnings growth and stock prices (and lower returns). Therefore, one explanation as to why inflation may affect stock return predictive power is the effect on risk over regimes of inflation.

Further, it is argued that higher inflation can mask fundamental signals emanating from economic variables through a money illusion effect. Ritter and Warr (2002) argue that the bull-run from the early 1980s was a result of more accurate market valuations that had previously been obscured by high and volatile inflation. The effect of money illusion is such that prices became relatively undervalued. Money illusion arises when investors determine stock prices through discounting real cash flows using nominal instead of real rates and was hypothesised by Modigliani and Cohn (1979), with supportive evidence presented in Campbell and Vuolteenaho (2004). Furthermore, as discussion by Cohen et al (2005) both the risk premium approach and the money illusion hypothesis suggest that higher inflation is linked to lower stock prices and while distinguishing between these alternate views is not the objective of this paper, they set out an approach to disentangle the effects in their paper.

Given the above, we obtain monthly data over the sample period 1963 month 1 to 2012 month 12. The stock price, earnings and dividend data is obtained from the website of Robert Shiller, while all the remaining data (Federal funds rate, 10-year and 3-month interest rates, inflation, industrial production and M2) is obtained via the website of the St Louis Federal Reserve. ${ }^{4}$ Table 1 presents summary statistics of the data, while Figure 1 plots the series. Notable in the graphs are the key economic events and crises during this period,

\footnotetext{
${ }^{4}$ www.econ.yale.edu/ shiller/data/ie_data.xls and https://research.stlouisfed.org/fred2/
} 
including the oil price shocks of the 1970s, the dotcom bubble and crash of the late 1990s and early 2000s and the financial crisis of the later 2000s.

\subsection{Stock Returns and Inflation: Summary Information}

To begin our analysis of the relation between stock returns and inflation across different regimes according to the level of inflation. Table 2 reports the average return (mean and median) for different level of inflation over the sample period, as well as a sub-period starting in 1980:1 to the end of the sample. ${ }^{5}$ The lower part of Table 2 repeats the same exercise using different values of the Federal Funds rate and the 10-year to 3-month Treasury bond term structure, in order to provide a level of robustness to the results.

The set of values in Table 2 present an interesting description of the stock return and inflation relation. Of note, there appears to be a rough U-shape pattern for average returns over different levels of inflation. Of particular note, the average return when inflation is below zero is very high (although dominated by only a few observations), while it is also notably large when inflation is below $1 \%$. The average return then decreases as inflation rises before increasing again when inflation is above $10 \%$ (5\% for the post 1980 s data set only). Similar patterns are found for the two interest rate series, with average returns decrease as rates rise before reaching a turning point and increasing again. These statistics are purely descriptive and the pattern is not exact but nonetheless provides an interesting view of how average returns vary.

\section{Linear Regression.}

In order to provide a baseline regression to the subsequent results, we begin with the usual predictive regression as follows:

\footnotetext{
${ }^{5}$ To a certain extent this sub-sample split is ad hoc, but the period from 1980 onwards is a lower inflation period than the proceeding one and thus adds robustness to the results.
} 


$$
r_{t+1}=\alpha+\sum_{i} \beta_{i} x_{i, t}+\varepsilon_{t+1}
$$

where $r_{t+1}$ is returns in excess of a 3-month Treasury bill measured over the subsequent time period (month), $x_{i, t}$ are the explanatory variables and $\varepsilon_{t+l}$ a random error term. In choosing the explanatory variables we are led by the literature on predictability and although this literature is voluminous and we cannot use all variables considered within the literature, we consider seven of the more prominent ones. We use several financial ratio that are argued to contain predictive power as a proxy for the expected return. This includes the dividend-price ratio (dp, Fama and French, 1988; Campbell and Shiller, 1988), the dividend-earnings ratio (de, Lamont, 1998) and the cyclically adjusted price-earnings ratio (CAPE, Campbell and Shiller, 1988). Additionally, we include several macroeconomic variables that indicate the level of economic activity. These include inflation, industrial production (as a measure of output), the term structure (TS) as the difference between the yield on a 10-year government bond and 3month Treasury bill and the change in the Federal Funds rate (dff). ${ }^{6}$

Table 3 reports the results of this regression. Examining the full sample results we can see that there is a positive and significant relation between future stock returns and the dividend-price ratio, with a weaker effect from the CAPE. A negative and significant relation is reported for the de, inflation, industrial production and $d f f$. For the remaining series (TS and the M2 growth rate) they are both negative but statistically insignificant. Examining the results for the sample that begins in 1980, the results are broadly similar although the significance of some variables changes. The $d p$ variable remains positive and statistically significant, while CAPE is now significant and still positive. Similarly, de remains negative and significant. For inflation, industrial production growth, and the two interest rate series,

\footnotetext{
${ }^{6}$ One issue that can arise within predictive regressions is the potential for persistence and endogeneity in any of the regressors to affect the estimates, often referred to as the Stambaugh (1999) bias. A recent set of papers has suggested a feasible quasi-GLS (FQGLS) $t$-test that is robust to both of these as well as heteroscedasticity (Westerlund and Narayan, 2012, 2015). As the focus in this paper is on non-linear effects, we refer the reader to this work but do not consider it further here.
} 
the relation remains negative but is only statistically significant for inflation. Money supply growth remains statistically insignificant although is now positive.

As noted above we can discuss these relations in terms of their effect on cash flow and risk and the prevailing beliefs underlying them. The positive relation between stock returns and $d p$ has been argued for forcibly by Cochrane $(2008,2011)$ as operating through the risk premium. A risk in the level of economic risk will be matched by a fall in the current price level, resulting in a rise in the $d p$ while also leading to a rise in future returns as compensation for the higher risk. The positive CAPE relation arises whereby higher earnings over a period of time leads to higher future dividends and hence returns (Campbell and Shiller, 1988). Lamont (1998) argues in favour of a positive coefficient between stock returns and $d e$. Lamont suggests that high dividends forecast high future returns, while high earnings are associated with high current prices, low macroeconomic risk and low future returns. The results here however support a negative relation. This perhaps suggests an explanation more akin to the CAPE where current high earnings (lower $d e$ ) support higher future dividends and in turn stock returns. The positive interest rate coefficient is consistent with, for example, Ang and Bekaert (2007) and suggests that higher interest rates are consistent with lower prices and higher returns due to increased macroeconomic risk. Furthermore, as a competing asset, higher bond yields would lead to higher equity yields and returns. Regarding the macroeconomic variables, the negative relation with $d f f$ is consistent with those reported by Thorbecke (1997), Rigobon and Sack (2004), Bernanke and Kuttner (2005) and Maio (2014), while the negative relation with inflation is consistent with the proxy hypothesis of Fama (1981). The negative relation with output suggests that an increase in industrial production growth is associated with a reduction in economic risk and subsequently a fall in returns.

As noted above however, it is not clear if these explanation for the relation with stock returns sit well across different levels of the explanatory variables. A given increase in 
inflation when the level of inflation is low or high is unlikely to elicit the same response in stock returns as the implications for economic risk differ. An increase in inflation at low levels indicates an economy recovering from an economic downturn, whereas the same increase in a high level of inflation points to an overheating economy that is likely to result in a policy response to dampen economic activity. Thus, the first scenario points towards a lowering of economic risk and the second to an increase in risk. Similar arguments could be presented to changes in interest rates and output growth at differing values of their respective level.

\section{Non-Linear Regression.}

Following the arguments above as well as the evidence portrayed in Table 2, we proceed in this section to estimate a threshold regression in which the level of inflation is taken as the threshold variable. The non-linear threshold model allows for multiple regimes of behaviour, according to some threshold variable, to exist. Taking a two-regime model as an example:

$$
r_{t}=\alpha+\left(\sum_{i} \beta_{i} x_{i t-1}\right)\left(z_{t-1}<\tau\right)+\left(\sum_{i} \delta_{i} x_{i t-1}\right)\left(z_{t-1}>\tau\right)+\varepsilon_{t}
$$

Where $z_{t-1}$ is the threshold variable and $\tau$ the threshold value.

The threshold value(s) and the number of regimes are estimated using the approach taken by Bai and Perron (1998) and consistent with the discussion in Hansen (1999, 2000). In each case the linear model is tested for breaks in the parameter values across the middle $70 \%$ of ordered values of the threshold variable. This test follows a sequential procedure of no break versus one break, one break versus two and so forth.

The resulting test statistics are reported in Table 4. Focusing on the results for inflation and for the whole sample, we can see that the null hypotheses of zero thresholds and of one threshold are rejected, while the null hypothesis of two thresholds is not rejected. Examining the shorter sample that begins in 1980, we can see that the null hypothesis of no 
thresholds is still rejected, although now the tests suggest only one threshold and hence two regimes. The identified threshold values are reported in the discussion of the results in Table 5. Discussion of the threshold tests for the interest rate series are noted later.

Having established the presence of threshold effects, the results of the threshold regression are reported in Table 5. Examining the full sample results it is of pertinent interest to note a change in sign for several of the predictor variables across the different inflation regimes. Inflation itself changes from a negative to a positive relation as the level of inflation increases. This is consistent with the argument made above that an increase in inflation from a low level of inflation indicates a recovering economy and so lower risk and expected returns (higher price), while an equivalent increase in inflation from a high level indicates an overheating economy and so an increase in economic risk with lower prices and an increasing expected return. A similar pattern is found regarding the money supply. An increase in M2 at low levels of inflation boosts an economic recovery and so returns fall, while higher money supply when inflation is already high further increases the likelihood of interest rate rises and so returns rise to compensate for heightened risk. Although the sign of the coefficient does not change, it can be observed that the strength of the relation arising from output growth weakens as inflation increases. Again, starting from the premise that an increase in output reduces economic risk, this again reflects our observation that this diminishes with higher inflation as it implies the potential for reactive monetary policy changes.

The results also suggests a difference in the behaviour of the financial ratios, which act as proxies for expected returns, over different inflation levels. The $d p$ remains positive throughout but is of greatest magnitude in the middle regime, it is also only statistically significant in this regime. The $d e$ is negative at low and middling inflation levels and positive at the higher level, while being significant in the latter two regimes. The CAPE is negative and insignificant at the lowest and highest inflation regimes and positive and significant in 
the middle regime. Collectively it is difficult to interpret these results but suggests that the linked between fundamentals, as proxied by these ratios, and subsequent stock returns varies over regimes of behaviour. Nonetheless, the results do suggest a difference between the way changes in dividends and earnings impact prices over different regimes of economic performance.

Table 5 also presents the results using the sub-sample starting from 1980. Here we can observe only two inflation regimes, which are broadly consistent with the first two regimes in the full sample. A high (above 5\%) inflation regime is not identified here. Such high inflation was largely a phenomenon of the 1970s. Nonetheless, again we can see the nature of the predictor variables changing over the inflation regimes. In terms of the financial ratios, the dividend-price ratio is significant in both regimes but is of greater magnitude and significance in the higher inflation regime. For the dividend-earnings ratio, this is negative in both regimes but again stronger in terms of (absolute) magnitude and significance in the higher inflation regime (indeed, it is not statistically significant in the lower regime). For the CAPE, while it is positive in both regimes it is not significant at the $5 \%$ level in either. For the interest rate series, only the term structure variable is (marginally) significant in any regime, this being the upper inflation one for the full sample. Inflation is significant across both regimes and again switches from a negative to a positive sign. Industrial production is not significant in either regime. Again, we can see money growth switching from a negative to positive value, indicating that the effect on risk of such growth depends on the state of the economy.

To complement the above analysis, we also consider interest rates as the potential switch given their positive relation with inflation. As noted in Table 2, both the change in the Federal funds rate and the term structure appear to have a similar relation with stock returns to that observed for inflation (perhaps, more so for the term structure). Table 4 presents the 
tests for threshold behaviour, similar to those presented for inflation earlier. As can be observed for the change in the Federal funds rate, there is no evidence of non-linear threshold behaviour. For the term structure, a single threshold (two regimes) is found for both the full sample and the post 1980 sample. Table 6 now presents the estimation results for this threshold model. We can observe from this table that there is less evidence of coefficient signs switching across the two regimes than we observed when inflation was utilised as the threshold variable (perhaps only noticeable for CAPE and money supply growth, albeit the coefficients on these variables are generally not statistically significant). For most series, the only noticeable change is in the magnitude of the coefficient. Particularly, this decreases from the low TS regime to the high TS regime, with the exception of the coefficients on the change in the Federal funds and term structure variables, although these coefficients are not significant for the latter series. These results suggest that the relation of many of the expected return proxies and economic variables with stock returns weakens when the term structure takes a larger value, although does not capture some of the key changes in the sign of the relation as occurs when inflation is used as the threshold variable.

\section{Alternative Non-Linear Model}

The analysis above has demonstrated a non-linear relation between stock returns and inflation. Notably with higher inflation associated with a positive relation with expected returns (i.e., higher inflation leads to a fall in share price), while a negative relation is noted at lower levels of inflation. These relations hold when we alternatively consider the term structure as opposed to inflation itself as the threshold variable. To provide further robustness to this result, we now consider an alternative regression model to examine if higher inflation gives rise to a differing relation. 
To this end, we introduce squared inflation in to our regression given by equation (1). The use of squared inflation will emphasise the effects of larger values and allows us to examine whether they behave differently in their relation with expected returns. The results of this regression are presented in Table 7 and demonstrate a difference in behaviour between inflation and squared inflation with respect to stock returns. Over the level of inflation has a negative relation with stock returns, as was identified in the linear regression models of Table 3. However, we can see that squared inflation has a positive relation with stock returns, suggesting that larger movements in inflation are consistent with increases in (expected) stock return and falling (current) prices. This, therefore, continues to support our view that stock returns and inflation exhibit a changing nature regarding their interaction. The remaining explanatory variables in Table 7 maintain a similar relation to that reported in Table 3.

\section{Forecasting.}

The previous sections have demonstrated the potential for threshold behaviour to exist in the relation between stock returns and its predictor variables according to the level of inflation. However, it is well-known in the predictability literature that there is the potential for instability within the predictive regression. In particular, Paye and Timmermann (2006) and Lettau and van Nieuwerburgh (2008) have consider the potential for shifts in either the coefficients or the predictor variable, while Timmermann (2008) argues in favour of localised predictability. The use of non-linear threshold regression may capture these effects or, alternatively, the threshold behaviour found may spuriously arise from such behaviour.

Thus, it is important to conduct an out-of-sample forecast exercise in order to examine the robustness of the above in-sample results. To consider this, we therefore conduct a rolling forecast exercise using a ten-year fixed window for the in-sample estimation and obtain 
return forecasts from the above linear and non-linear threshold models. We begin with a fixed window of 120 observations and estimate each forecast model over the period 1963:1 to 1972:12 and obtain the forecast for the next period, 1973:1. The sample is then rolled forward as 1963:2 to $1973: 1$ and the forecast obtained for 1973:2. This process continues until the end of the sample is reached. For the threshold models, we re-consider the threshold values at each step. Overall, the exercise in intended to replicate the situation faced by a trader operating in real time.

In order to evaluate the forecasts we consider a range of different metrics designed to capture different aspects of forecast accuracy, including the magnitude of the forecast error, the ability to forecast the direction (sign) correctly and the ability to provide a successful trading strategy. We begin with three standard statistical metrics used in forecast evaluation, namely the mean error (ME), mean absolute error (MAE) and the root mean squared error (RMSE) metric as such:

$$
M E_{i}=\frac{1}{\tau} \sum_{t=1}^{\tau}\left(r_{t}-r_{t}^{f_{i}}\right)
$$

$$
R A E_{i}=\frac{1}{\tau} \sum_{t=1}^{\tau}\left(\left|r_{t}-r_{t}^{f_{i}}\right|\right)
$$

where $r_{t}$ is the actual return, $r_{t}^{f_{i}}$ is the forecast with $i=1, \ldots, 3$ for each model respectively.

To further develop a comparison between models we use the out-of-sample R-squared measure previously considered by Campbell and Thompson (2008) and Welch and Goyal (2008) and a forecast encompassing test following Fair and Shiller (1989), see Clements and Harvey (2009). The out-of-sample R-squared measure is given by:

$$
R_{\text {oos }}^{2}=1-\left(\frac{\sum_{t=1}^{\tau}\left(r_{t}-\hat{r}_{t, \text { alt }}\right)^{2}}{\sum_{t=1}^{\tau}\left(r_{t}-\hat{r}_{t, \text { base }}\right)^{2}}\right)
$$


where $\tau$ is the forecast sample size, $r_{t}$ is the actual return, $\hat{r}_{t, a l t}$ is the forecast value obtained from the alternate (non-linear) model and $\hat{r}_{t, b a s e}$ is the baseline (linear) forecast. Where the $R_{\text {oos }}^{2}$ value is positive then the alternative predictive model has greater forecasting power than the baseline forecast model. The forecast encompassing test regression is given as:

$$
r_{t}=\alpha+\beta_{1} \hat{r}_{t, b a s e}+\beta_{2} \hat{r}_{t, a l t}+\varepsilon_{t}
$$

again $r_{t}$ is the actual return, $\hat{r}_{t, a l t}$ is the forecast value obtained from the non-linear threshold model and $\hat{r}_{t, b a s e}$ is the baseline linear model. In the forecast encompassing approach the baseline forecast is said to encompass the alternative model forecast if $\beta_{2}$ is statistically insignificant. However, if $\beta_{2}$ is positive and statistically significant then the alternative model contains information that is beneficial for forecasting that is not captured by the baseline model.

The above metrics measure the size of the forecast error. To examine the ability of each model to correctly forecast the return sign we first employ the straightforward success ratio (SR) measure. The SR reports the percentage of correctly forecast signs as such:

$$
S R=\sum_{t=1}^{\tau} s_{t} \text { where } s_{t}=I\left(r_{t} r_{t}^{f_{i}}>0\right)=1 ; 0 \text { otherwise }
$$

therefore, a SR value of one would indicate perfect sign predictability and a value of zero would indicate no sign predictability. More generally, and following Cheung et al (2005), a value of greater than 0.5 would indicate performance better than chance (more strictly, a random walk with a constant drift). Related to the success ratio is the market timing (MT) test of Pesaran and Timmermann (1992). This test compares the obtained success ratio with an estimate of the probability that the actual and forecast series can have the same sign independently ( $\hat{P}_{*}$ below). Hence, MT tests the null that the actual and forecast series are independently distributed and thus there is no sign predictive power: 


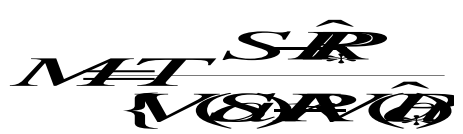

where $\hat{P}_{*}=\hat{P}_{r} \hat{P}_{f^{f_{i}}}+\left(1-\hat{P}_{r}\right)\left(1-\hat{P}_{r_{i}}\right)$ with $\widehat{P}_{r}=\sum_{\tau=1}^{\tau} \boldsymbol{P}_{\left.v_{i}>0\right\}}$ and $\hat{P}_{\hat{r}}=\frac{1}{\tau} \sum_{t=1}^{\tau} I_{\left\{r_{f_{i}}>0\right\}}$.

To complement the above statistical forecast analysis, we provide an additional trading based forecast (although the SR and MT tests do provide some trading information with respect to buy and sell signals). To examine this approach we begin with a simple trading rule that states if the forecast for next periods return is positive then buy the stock, while if the forecast for the next periods return is negative, then we can either take no position (i.e., if no short selling is allowed) or sell the asset (if short selling is allowed). This allows us to obtain a time series for trading returns, which we can denote, $\pi$, recalling again that these are returns in excess of the 3-month Treasury bill. To provide information relevant to market participants, we can then use this time series to generate the Sharpe ratio for each model as such:

$$
\operatorname{SHARPE}_{i}=\frac{\bar{\pi}}{\sigma}
$$

where, for example following Burnside et al (2010) and Moosa and Burns (2014), the Sharpe ratio is calculated as the ratio of the mean trading profit $(\bar{\pi})$ and the standard deviation $(\sigma)$. A model that produces a higher Sharpe ratio therefore has superior risk-adjusted returns.

The results of the forecast evaluations for the four models are reported in Table 8 . The results for the ME are supportive of the linear model. However, while the ME provides a basic view of potential bias in the forecasts, a well-known drawback is that positive and negative forecast errors can offset such that a small ME may hide large errors. Hence, the use of the MAE and RMSE, which eliminate the sign of the forecast errors, the MAE does so proportionately, while the RMSE emphasises larger errors. On both of these measures, the 
non-linear threshold model, with inflation as the threshold variable achieves the lowest value and so is preferred.

The out-of-sample R-squared and the forecast encompassing tests are designed to provide further comparative performance between the linear and non-linear models. The first test examines the ratio of squared errors where a positive value supports the non-linear model. We can see that for both threshold approaches, this value is indeed positive. Furthermore, it is larger for the threshold model that uses inflation as the threshold variable. For the squared inflation models, the value is negative, supporting the linear model. The second test considers which forecast can account for the largest proportion of variance in the actual return series using the linear forecast as the baseline. Should the value here be positive and statistically significant then it suggests the alternate non-linear forecast does provide additional information in explaining the movement of returns. Both the threshold forecast suggest that they are not encompassed by the linear forecast as they have positive and significant coefficients. Moreover, the value of one for the inflation threshold model suggests that its forecasts provide unbiased estimates of returns. Again, the squared inflation forecast does not outperform the linear model.

The success ratio test examines the proportion of correctly signed forecasts while the market timing test provides a measure of statistical robustness to that value by comparing the success ratio to chance occurrence. For all four forecast models the value of the success ratio is greater than $50 \%$, which is effectively the random walk benchmark. This time the squared inflation model achieves the highest success ration, while the threshold model with inflation as the threshold variable achieves the second highest ratio. Furthermore, for all four forecast models the market timing test is statistically significant (although less so for the squared inflation model). This suggests that the achieved success ratio values are not obtained by 
chance but that each of the forecast models do provide information as to the direction of the market, which could be used by investors in utilising a trading strategy.

To consider this final point further we generate the Sharpe ratio from two trading strategies, one involving short selling and the other disallowing it. The results in Table 5 for this exercise present several interesting conclusions. First, for all forecast models the values of the Sharpe ratios are positive suggesting some value in these forecast models. Second, the Sharpe ratio values that allow short selling are greater than those that do not allow short selling. Again, this suggests some value in allowing such trading to occur. Third, both threshold models provide a higher Sharpe ratio value compared to the linear forecast model, with the non-linear model that uses inflation as the switching variable preferred. As noted before, the linear models performs better than the squared inflation model.

Overall, the combined nature of the forecast results heavily supports both non-linear threshold models over the linear model and the inflation threshold variable model in particular. Only for the ME does the linear model provide a preferred value, for all other forecast measures both threshold models are preferred over the linear model, with the inflation threshold model achieving the best performance. For the squared inflation model, while its in-sample estimates support the identified relation between stock returns and inflation, its forecast performance is weak, with the sole exception of the success ratio.

\section{Summary and Conclusion.}

This paper examines whether the ability to predict stock market returns varies over regimes according to the level of inflation and, in particular, seeks to piece together two elements from the exiting literature on predictability. First, that evidence in favour of predictability is

mixed and second, that there remains a firm belief that predictability should be linked to explicit economic variables. We argue that the mixed nature of the results arises from non- 
linear behaviour within the relation between stock returns and the predictor variables. For example, an equal increase in inflation from a low or high level has different implications for risk and thus expected returns. The former suggests improving economic conditions leading to lower future returns and the latter to declining economic prospects and rising expected returns. However, we can add to that where a very low level of inflation would also be consistent with poor economic prospect and higher returns. We illustrate this with initial descriptive results that show higher returns occurring with both the lowest and higher levels of inflation, while lower returns occur with low and intermediate inflation values.

We conduct a linear and, after appropriate testing, two non-linear threshold regressions. These regressions are estimated over the monthly sample from 1963 to 2012 as well as from 1980 to 2012. Estimation of the linear model produces some results that may be viewed as counter-intuitive. For example, higher earnings should lead to higher current stock prices and lower future returns thus producing a positive relation with $d p$ and $d e$, however, the reported result for the latter is negative. Estimation of the non-linear model where inflation acts as the threshold variable demonstrates that several of the predictor variables have coefficients whose sign switches across regimes. Again, as an example and consistent with our discussion above, inflation has a negative relation with future returns when inflation is low but a positive relation when inflation is high. Similar effects occur with other variables. An alternative threshold model based on the term structure provides similar but distinct results, with less indication of sign switching but still demonstrates noticeable changes in coefficient magnitude.

In comparing the models, measures of in-sample fit support the threshold models, however, to provide greater robustness, we subject our models to a rolling forecast exercise. Forecast metrics based on the size of the forecast error, the sign of the forecast error and a trading rule all are supportive of the threshold approach and in particular when inflation is 
used as the threshold variable. Specifically, this forecast model produces the lowest MAE and RMSE, the most significant forecast encompassing test and the highest success ratio, market timing test and Sharpe ratios. It is hoped that the results presented here go some way towards explaining the mixed nature of the stock return predictability results. Our belief is that stock returns are related to economic variables, however, consistent empirical evidence for that belief is missing. This paper argues that is because the nature of the relation varies over time with inflation. It is hoped these results re useful to both academics involved in developing theoretical models of stock market behaviour and to practitioners in understanding the movement of markets and thus in the development of market timing strategies as well as portfolio and risk management. 


\section{References}

Ang, A., and Bekaert, G. (2007). Stock Return Predictability: Is it There? Review of Financial Studies, 20: 651-707.

Bai, J and Perron, P, (1998), 'Estimating and testing linear models with multiple structural changes', Econometrica, 66, 47-78.

Bampinas G. and Panagiotidis T., (2016), 'Hedging inflation with individual US stocks: A long-run portfolio analysis', North American Journal of Economics and Finance, 37, 374392.

Bannigidadmath, D and Narayan, PK (2016), 'Stock return predictability and determinants of predictability and profits’, Emerging Markets Review, 26, 153-173.

Bernanke, BS and Kuttner, KN, (2005), 'What explains the stock market's reaction to Federal Reserve policy?', Journal of Finance, 60, 1221-1257.

Bodie, Z, (1976), 'Common stocks as a hedge against inflation', Journal of Finance, 31, 459470.

Burnside, C., Eichenbaum, M., Kleshcelski, I. and Rebelo, S. (2010), 'Do peso problems explain the returns to the carry trade', Review of Financial Studies, 24, 853-891.

Campbell, J.Y., and Shiller, R.J., (1988a). The dividend-price ratio and expectations of future dividends and discount factors. Review of Financial Studies 1, 195-228.

Campbell, JY and Thompson, SB, (2008). 'Predicting excess stock returns out of sample: Can anything beat the historical average?' Review of Financial Studies, 21, 1509-1531.

Campbell, JY and Yogo, M, (2006), 'Efficient tests of stock return predictability,' Journal of Financial Economics, 81, 27-60.

Campbell, JY and Vuolteenaho, Y, (2004), 'Inflation illusion and stock prices', American Economic Review Papers and Proceedings, 19-23.

Cheung, Y-W, Chinn, MD and Pascual, AG (2005), 'Empirical exchange rate models of the nineties: are they fit to survive?', Journal of International Money and Finance, 24, 11501175 .

Clements, MP and Harvey, DI, (2009), 'Forecast combination and encompassing', Palgrave Handbook of Econometrics, vol. 2, Applied Econometrics, 169-198.

Cochrane, J. (2008). The Dog that did not Bark: A Defense of Return Predictability. Review of Financial Studies 21: 1533-1575.

Cochrane, J, (2011), 'Discount rates: American finance association presidential address', Journal of Finance, 66, 1047-1108. 
Cohen, RB, Polk, C, Vuolteenaho, Y (2005), 'Money illusion in the stock market: The Modigliani-Cohn hypothesis', Quarterly Journal of Economics, 2, 630-668.

Eggertsson, G.B. and Krugman, P. (2012). 'Debt, Deleveraging, and the Liquidity Trap: A Fisher-Minsky-Koo Approach’, Quarterly Journal of Economics, 127, 1469-1513.

Engsted, T and Pedersen, TQ, (2010), 'The dividend-price ratio does predict dividend growth: International evidence', Journal of Empirical Finance, 17, 585-605.

Fair, RC and and Shiller, RJ, (1989), 'The informational content of ex ante forecasts', Review of Economics and Statistics, 71, 325-331.

Fama, E, (1981), 'Stock returns, real activity, inflation and money', American Economic Review, 71, 545-565.

Fama, E.F., and French, K.R., (1988). Dividend yields and expected stock returns. Journal of Financial Economics 22, 3-25.

Fama, EF and Schwert, GW, (1977), 'Asset returns and inflation', Journal of Financial Economics, 5, 115-146.

Fisher, I, (1930), The Theory of Interest, Macmillan, New

Gertler, M and Karadi, P, (2013), 'Monetary policy surprises, credit costs and economic activity', working paper, NYU.

Goyal, A and Welch, I (2003), 'Predicting the equity premium with dividend ratios', Management Science, 49, 639-654.

Guidolin, M. Hyde, S, McMillan, DG and Ono, S (2009), 'Non-Linear Predictability in Stock and Bond Returns: When and Where Is It Exploitable?', International Journal of Forecasting, 25, 373-399.

Hansen, BE, (1999), ‘Testing for linearity’, Journal of Economic Surveys, 13, 551-576.

Hansen, BE, (2000), 'Testing for structural change in conditional models', Journal of Econometrics, 97, 93-115.

Hanson, S and Stein, JC, (2012), 'Monetary policy and long-term real rates', Harvard Business School Working Paper, No. 13-008.

Henkel, SJ, Martin, JS and Nardari, F, (2011), 'Time-varying short-horizon predictability', Journal of Financial Economics, 99, 560-580.

Hjalmarsson, E (2010), 'Predicting global stock returns,' Journal of Financial and Quantitative Analysis, 45, 49-80.

Ilmanen, A. (2003), ‘Stock-Bond Correlations', Journal of Fixed Income, 13, 55-66. 
Kellard, NM, Nankervis, JC and Papadimitriou, FI, (2010), 'Predicting the equity premium with dividend ratios: Reconciling the evidence', Journal of Empirical Finance, 17, 539-551.

Lamont, O, (1998), 'Earnings and expected returns', Journal of Finance, 53, 1563-1587.

Lettau, M and Van Nieuwerburgh, S, (2008), 'Reconciling the return predictability evidence', Review of Financial Studies, 21, 1607-1652.

Maio, P, (2014), 'Another look at the stock return response to monetary policy actions', Review of Finance, 18, 321-371.

McMillan, DG, (2003), 'Non-Linear Predictability of UK Stock Market Returns' Oxford Bulletin of Economics and Statistics, 65, 557-573.

McMillan, DG (2014), 'Modelling Time-Variation in the Stock Return-Dividend Yield Predictive Equation', Financial Markets, Institutions and Instruments, 23, 273-302.

McMillan, DG and Wohar, ME, (2010), 'Stock return predictability and dividend-price ratio: A nonlinear approach', International Journal of Finance and Economics, 15, 351-365.

McMillan, DG and Wohar, ME, (2013), 'A panel analysis of the stock return dividend yield relation: predicting returns and dividend growth', Manchester School, 81, 386-400.

Modigliani, F and Cohn, R (1979), 'Inflation, Rational Valuation, and the Market', Financial Analysts Journal, 35, 24-44.

Moosa, I and Burns, K, (2014), 'The unbeatable random walk in exchange rate forecasting: Reality or myth?', Journal of Macroeconomics, 40, 69-81.

Narayan, PK and Bannigidadmath, D (2015), 'Are Indian stock returns predictable?', Journal of Banking and Finance, 58, 506-531.

Park, C (2010), 'When does the dividend-price ratio predict stock returns?,' Journal of Empirical Finance, 17, 81-101.

Paye, B., and Timmermann, A. (2006). Instability of return prediction models. Journal of Empirical Finance, 13, 274-315.

Pesaran, MH and Timmermann, A (1992), 'A simple nonparametric test of predictive performance', Journal of Business and Economic Statistics, 10, 461-465.

Pesaran, MH and Timmermann, A (1995). 'Predictability of stock returns: robustness and economic significance', Journal of Finance, 50, 1201-1228.

Pesaran, MH and Timmermann, A (2000). 'A recursive modelling approach to predicting UK stock returns', Economic Journal, 110, 159-191.

Phan, DHB, Sharma, SS and Narayan, PK (2015), 'Stock return forecasting: Some new evidence', International Review of Financial Analysis, 40, 38-51. 
Psaradakis, Z, Sola, M and Spagnolo, F (2004), 'On Markov error-correction models, with an application to stock prices and dividends', Journal of Applied Econometrics, 19, 69-88.

Rigobon, R and Sack, B, (2004), 'The impact of monetary policy on asset prices', Journal of Monetary Economics, 51, 1553-1575.

Ritter, J and Warr, R (2002), 'The decline of inflation and the bull market of 1982 to 1999', Journal of Financial and Quantitative Analysis, 37, 29-61.

Sellin, P, (2001), 'Monetary policy and the stock market: Theory and Empirical Evidence', Journal of Economic Surveys, 15, 491-541.

Sharpe, S (2001), 'Re-examining stock valuation and inflation: the implications of analysts' earnings forecasts', Finance and Economic Discussion Series 200132, Board of Governors of the Federal Reserve.

Shiller, R.J. and Belratti, A.E. (1993). 'Stock Prices and Bond Yields: Can their Comovements be explained in Terms of Present Value Models?' Journal of Monetary Economics, 30, 25-46.

Thorbecke, W, (1997), 'On stock market returns and monetary policy', Journal of Finance, $52,635-654$.

Timmermann, A, (2008), 'Elusive return predictability', International Journal of Forecasting, 24, 1-18.

Welch, I and Goyal, A (2008), 'A comprehensive look at the empirical performance of equity premium prediction', Review of Financial Studies, 21, 1455-1508.

Westerlund, J, Narayan, PK and Zheng, X (2015), 'Testing for stock return predictability in a large Chinese panel', Emerging Markets Review, 24, 81-100.

Westerlund, J and Narayan, PK (2012), 'Does the choice of estimator matter when forecasting returns?', Journal of Banking and Finance, 36, 2632-2640.

Westerlund, J and Narayan, PK (2015), 'Testing for predictability in conditionally heteroskedastic stock returns', Journal of Financial Econometrics, 13, 342-375. 
Table 1. Summary Statistics

\begin{tabular}{|c|c|c|c|c|}
\hline & Mean & Std. Dev. & Skewness & Kurtosis \\
\hline Excess Returns & 0.478 & 3.653 & -1.002 & 7.012 \\
\hline Log Div. Yield & -3.572 & 0.412 & -0.330 & 2.282 \\
\hline $\log \mathrm{D} / \mathrm{E}$ & -0.753 & 0.324 & 2.835 & 17.951 \\
\hline CAPE & 19.499 & 8.203 & 0.773 & 3.580 \\
\hline Ch. FF & -0.005 & 0.559 & -2.218 & 44.008 \\
\hline $\mathrm{TS}$ & 2.491 & 1.245 & 0.275 & 2.879 \\
\hline Inflation & 4.094 & 2.717 & 1.379 & 4.880 \\
\hline IP Growth & 2.661 & 4.795 & -1.182 & 5.124 \\
\hline M2 Growth & 6.692 & 2.814 & 0.002 & 2.763 \\
\hline \multicolumn{5}{|c|}{$\begin{array}{l}\text { Notes: Numbers represent the values of the mean, standard deviation, skewness and } \\
\text { kurtosis for our series. Excess Returns are the S\&P Composite in excess of the 3-month } \\
\text { Treasury bill. The stock market data is from the website of Robert Shiller. The } \\
\text { macroeconomic data is from the St Louis Federal Reserve website. The sample period is } \\
\text { 1963:1 to 2012:12. }\end{array}$} \\
\hline
\end{tabular}


Table 2. Average Stock Return across

Difference Values of Inflation and the Federal Funds Rate

\begin{tabular}{|c|c|c|c|c|}
\hline & \multicolumn{2}{|c|}{$1963-2012$} & \multicolumn{2}{|c|}{$1980-2012$} \\
\hline & Mean & Median & Mean & Median \\
\hline Range (\%) & \multicolumn{4}{|c|}{ Inflation } \\
\hline$<0$ & 4.53 & 2.99 & 4.53 & 2.99 \\
\hline $0-2$ & 0.86 & 1.35 & 0.86 & 1.59 \\
\hline $2-5$ & 0.42 & 0.63 & 0.46 & 0.65 \\
\hline $5-7$ & 0.35 & 0.21 & 1.26 & 1.89 \\
\hline $7-10$ & -0.53 & 0.003 & -1.30 & -2.13 \\
\hline$>10$ & 0.35 & 1.88 & 0.55 & 2.34 \\
\hline Range (\%) & \multicolumn{4}{|c|}{ Federal Funds } \\
\hline$<1$ & 0.84 & 1.97 & 0.84 & 1.97 \\
\hline $1-3$ & -0.68 & -0.18 & -0.67 & -0.11 \\
\hline $3-5$ & 0.46 & 0.65 & 0.21 & 0.54 \\
\hline $5-7$ & 1.02 & 1.00 & 1.25 & 1.38 \\
\hline $7-10$ & 0.29 & 0.67 & 0.79 & 1.57 \\
\hline$>10$ & -0.23 & 0.21 & 0.27 & 0.10 \\
\hline Range (\%) & \multicolumn{4}{|c|}{ Term Structure (10yr - 3mth) } \\
\hline$<0$ & 0.26 & -0.38 & -0.16 & -1.32 \\
\hline $0-1$ & 0.76 & 1.06 & 0.75 & 0.81 \\
\hline $1-2$ & 0.41 & 1.11 & 0.96 & 1.81 \\
\hline $2-3$ & 0.62 & 0.80 & 0.73 & 0.91 \\
\hline $3-4$ & 0.37 & 0.38 & 0.31 & 0.63 \\
\hline $4-5$ & 0.62 & 0.93 & 0.62 & 1.03 \\
\hline$>5$ & 1.64 & 0.40 & 1.64 & 0.40 \\
\hline \multicolumn{5}{|c|}{$\begin{array}{l}\text { Notes: Numbers represent the average value of monthly excess stock returns (S\&P } \\
\text { Composite index minus the 3-month Treasury bill rate) according to different values of } \\
\text { annual inflation, the Federal Funds rate and the Term Structure (defined as the 10-year } \\
\text { bond minus the 3-momnth bill) given in the first column. All numbers are expressed as a } \\
\text { percentage. }\end{array}$} \\
\hline
\end{tabular}


Table 3. Linear Regression Results.

\begin{tabular}{|l|l|l|}
\hline Variable & $1963-2012$ & $1980-2012$ \\
\hline Dividend-Price Ratio & $4.845(3.07)$ & $9.626(3.14)$ \\
\hline Dividend-Earnings Ratio & $-2.760(-2.75)$ & $-2.782(2.59)$ \\
\hline CAPE & $0.096(1.60)$ & $0.259(2.56)$ \\
\hline Change in Federal Funds & $-0.691(-2.86)$ & $-0.413(-1.51)$ \\
\hline Term Structure & $-0.046(-0.41)$ & $-0.341(-1.42)$ \\
\hline Inflation & $-0.497(-4.34)$ & $-0.501(-2.87)$ \\
\hline Ind. Prod. Growth & $-0.135(-2.55)$ & $-0.093(-1.15)$ \\
\hline Change in M2 & $-0.017(-0.33)$ & $0.009(0.13)$ \\
\hline Adjusted R-squared & 0.057 & 0.059 \\
\hline AIC & 5.385 & 5.449 \\
\hline BIC & 5.452 & 5.540 \\
\hline $\begin{array}{l}\text { Notes: Entries are coefficient values (with Newey-West } t \text {-statistics) and related } \\
\text { specification measures based on equation (1). }\end{array}$ \\
\hline
\end{tabular}


Table 4. Non-Linear Tests:

Bai-Perron Sequentially Determined Thresholds

\begin{tabular}{|c|c|c|c|c|}
\hline $\begin{array}{c}\text { Test: \# of } \\
\text { Thresholds }\end{array}$ & Inflation & Change in FF & Term Structure & Critical Value \\
\hline \multicolumn{5}{|c|}{ Sample 1963:1-2012:12 } \\
\hline 0 vs 1 & 31.72 & 16.76 & 29.40 & 25.65 \\
\hline 1 vs 2 & 33.34 & - & 20.18 & 27.66 \\
\hline 2 vs 3 & 17.05 & - & & 28.91 \\
\hline \multicolumn{5}{|c|}{ Sample 1980:1-2012:12 } \\
\hline 0 vs 1 & 54.29 & 23.93 & 27.20 & 25.65 \\
\hline 1 vs 2 & 12.35 & - & 16.44 & 27.66 \\
\hline $\begin{array}{l}\text { Notes: The Bai-Perron Test is conducted sequentially and thus the testing procedure stops } \\
\text { then the null cannot be rejected. In testing we allow for five potential thresholds. }\end{array}$ \\
\hline
\end{tabular}


Table 5. Non-Linear Regression Results - Inflation as the Threshold Variable.

\begin{tabular}{|c|c|c|}
\hline Variable & $1963-2012$ & 1980-2012 \\
\hline & Inflation Regime $<3.97 \%$ & Inflation Regime $<3.94 \%$ \\
\hline Dividend-Price Ratio & $1.614(1.02)$ & $6.058(2.38)$ \\
\hline Dividend-Earnings Ratio & $-1.406(1.59)$ & $-1.648(-1.50)$ \\
\hline CAPE & $-0.009(-0.15)$ & $0.139(1.56)$ \\
\hline Change in Federal Funds & $-0.677(-0.82)$ & $-0.628(-0.61)$ \\
\hline Term Structure & $-0.084(-0.40)$ & $-0.426(-1.67)$ \\
\hline Inflation & $-0.666(-2.69)$ & $-0.776(-2.53)$ \\
\hline Ind. Prod. Growth & $-0.018(-0.27)$ & $-0.023(-0.25)$ \\
\hline Change in $\mathrm{M} 2$ & $-0.042(-0.66)$ & $-0.026(-1.56)$ \\
\hline & $\begin{array}{l}\text { Inflation } \quad \text { Regime } 3.97- \\
5.32 \%\end{array}$ & Inflation Regime $>3.94 \%$ \\
\hline Dividend-Price Ratio & $30.679(5.90)$ & $30.414(3.77)$ \\
\hline Dividend-Earnings Ratio & $-14.773(-5.36)$ & $-13.412(-5.09)$ \\
\hline CAPE & $1.177(3.53)$ & $0.798(1.70)$ \\
\hline Change in Federal Funds & $-0.060(-0.05)$ & $-0.156(-0.49)$ \\
\hline Term Structure & $0.401(0.94)$ & $0.327(1.08)$ \\
\hline Inflation & $0.259(1.95)$ & $0.438(2.51)$ \\
\hline Ind. Prod. Growth & $-0.250(-2.36)$ & $-0.021(-0.18)$ \\
\hline Change in M2 & $0.065(0.26)$ & $0.801(2.53)$ \\
\hline & Inflation Regime $>5.32 \%$ & \\
\hline Dividend-Price Ratio & $7.178(1.28)$ & \\
\hline Dividend-Earnings Ratio & $17.522(2.14)$ & \\
\hline CAPE & $-0.109(-0.24)$ & \\
\hline Change in Federal Funds & $-0.726(-2.51)$ & \\
\hline Term Structure & $-0.658(-1.94)$ & \\
\hline Inflation & $0.605(2.11)$ & \\
\hline Ind. Prod. Growth & $-0.007(-0.07)$ & \\
\hline Change in M2 & $0.523(2.38)$ & \\
\hline Adjusted R-squared & 0.129 & 0.165 \\
\hline AIC & 5.335 & 5.336 \\
\hline BIC & 5.435 & 5.445 \\
\hline
\end{tabular}


Table 6. Non-Linear Regression Results - Term Structure as the Threshold Variable.

\begin{tabular}{|c|c|c|}
\hline Variable & $1963-2012$ & 1980-2012 \\
\hline & TS Regime $<2.54 \%$ & TS Regime $<2.62 \%$ \\
\hline Dividend-Price Ratio & $9.318(4.22)$ & $5.871(1.73)$ \\
\hline Dividend-Earnings Ratio & $-7.898(-5.23)$ & $-4.336(-2.06)$ \\
\hline CAPE & $0.233(2.70)$ & $0.106(0.88)$ \\
\hline Change in Federal Funds & $-0.737(-2.19)$ & $-0.511(-1.35)$ \\
\hline Term Structure & $-0.265(-0.76)$ & $-0.129(-0.30)$ \\
\hline Inflation & $-0.775(-5.55)$ & $-0.566(-2.65)$ \\
\hline Ind. Prod. Growth & $-0.192(-2.43)$ & $0.162(1.10)$ \\
\hline \multirow[t]{2}{*}{ Change in M2 } & $-0.179(-1.58)$ & $-0.034(-0.22)$ \\
\hline & TS Regime $>2.54 \%$ & TS Regime $>2.62 \%$ \\
\hline Dividend-Price Ratio & $2.016(0.88)$ & $2.125(0.70)$ \\
\hline Dividend-Earnings Ratio & $-1.220(-1.37)$ & $-2.022(-1.98)$ \\
\hline CAPE & $-0.044(-0.33)$ & $-0.089(-0.48)$ \\
\hline Change in Federal Funds & $-0.947(-2.07)$ & $-0.790(-1.44)$ \\
\hline Term Structure & $-0.413(-1.41)$ & $-0.302(-0.83)$ \\
\hline Inflation & $-0.413(-2.78)$ & $-0.533(-3.11)$ \\
\hline Ind. Prod. Growth & $-0.119(-2.31)$ & $-0.231(-3.05)$ \\
\hline Change in M2 & $0.090(1.19)$ & $0.201(1.64)$ \\
\hline Adjusted R-squared & 0.088 & 0.094 \\
\hline AIC & 5.374 & 5.438 \\
\hline $\mathrm{BIC}$ & 5.508 & 5.620 \\
\hline
\end{tabular}


Table 7. Alternative Non-Linear Regression Model Results.

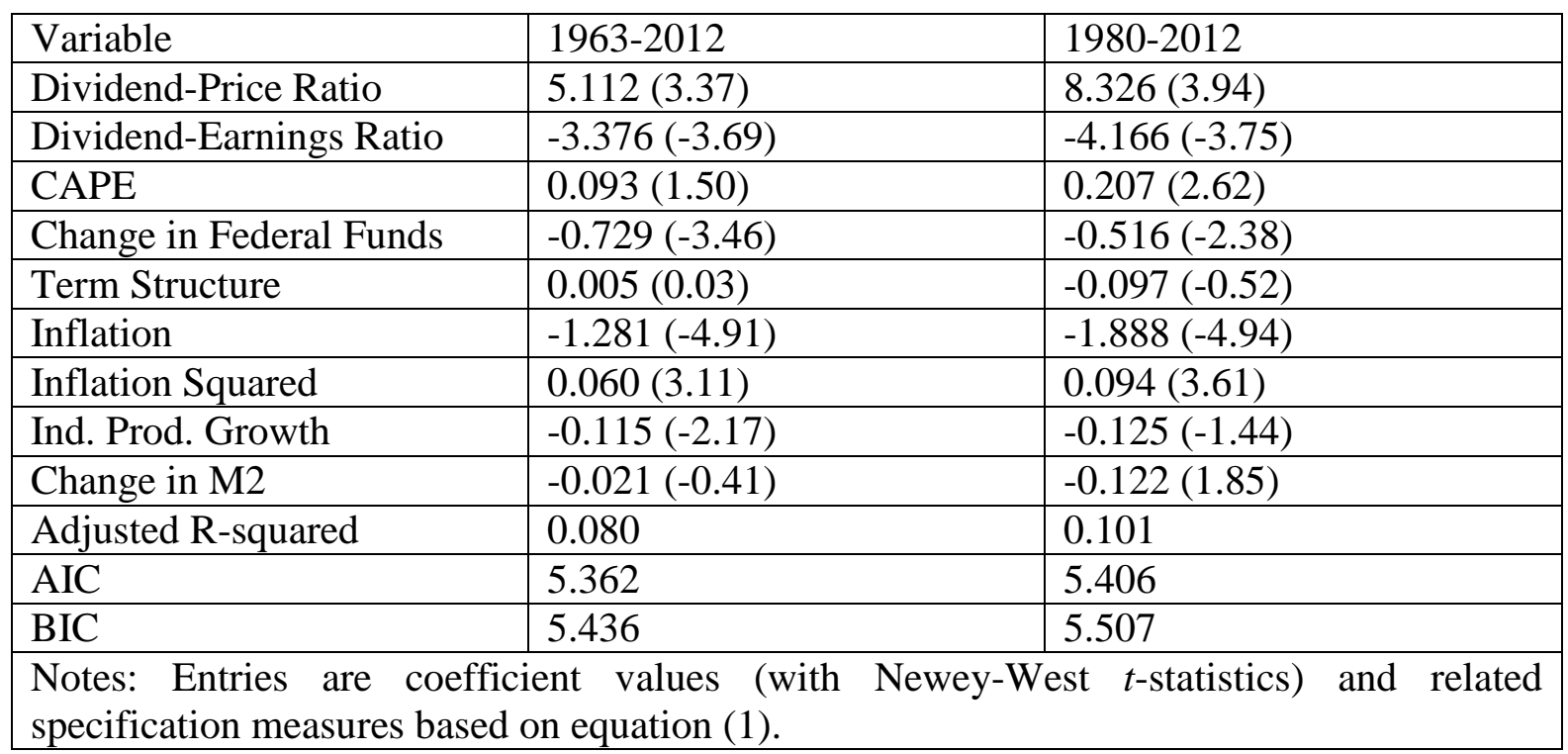


Table 8. Forecasting Results

\begin{tabular}{|l|l|l|l|l|}
\hline Forecast Measure & Linear & $\begin{array}{l}\text { Threshold } \\
\text { Infl. }\end{array}$ & $-\begin{array}{l}\text { Threshold } \\
\text { Term Str. }\end{array}$ & $\begin{array}{l}\text { Inflation } \\
\text { Squared }\end{array}$ \\
\hline ME & $-0.0052^{*}$ & -0.1172 & -0.0090 & -0.0855 \\
\hline MAE & 2.5455 & $2.3268^{*}$ & 2.4345 & 2.9393 \\
\hline RMSE & 3.4236 & $3.0526^{*}$ & 3.2647 & 4.0053 \\
\hline OOS - R sq. & - & $0.2050^{*}$ & 0.0882 & -0.3581 \\
\hline $\begin{array}{l}\text { Forecast } \\
\text { Encompassing }\end{array}$ & $\begin{array}{l}0.048 \\
(0.36)\end{array}$ & $\begin{array}{l}1.003^{*} \\
(11.04)\end{array}$ & - & - \\
\cline { 2 - 5 } & $\begin{array}{l}0.005 \\
(0.03)\end{array}$ & - & $\begin{array}{l}1.147 \\
(7.06)\end{array}$ & - \\
\hline $\begin{array}{l}1.207 \\
(7.58)\end{array}$ & - & - & -0.150 \\
& 0.61 & 0.65 & 0.63 & $0.70 *$ \\
\hline Success Ratio & 4.36 & $6.06^{*}$ & 5.36 & 2.14 \\
\hline Mkt. Timing & $0.424^{*}$ & 0.376 & 0.228 \\
\hline $\begin{array}{l}\text { Sharpe Ratio } \\
\text { (SS) }\end{array}$ & 0.347 & $0.329^{*}$ & 0.305 & 0.199 \\
\hline $\begin{array}{l}\text { Sharpe Ratio } 2 \text { NSS) } \\
\text { Notes: Entries are the forecast measures from equations } \\
\text { preferred forecast model. }\end{array}$ & $0.294)-(10)$. An asterisk denotes the \\
\hline
\end{tabular}


Figure 1. Time Series Plots
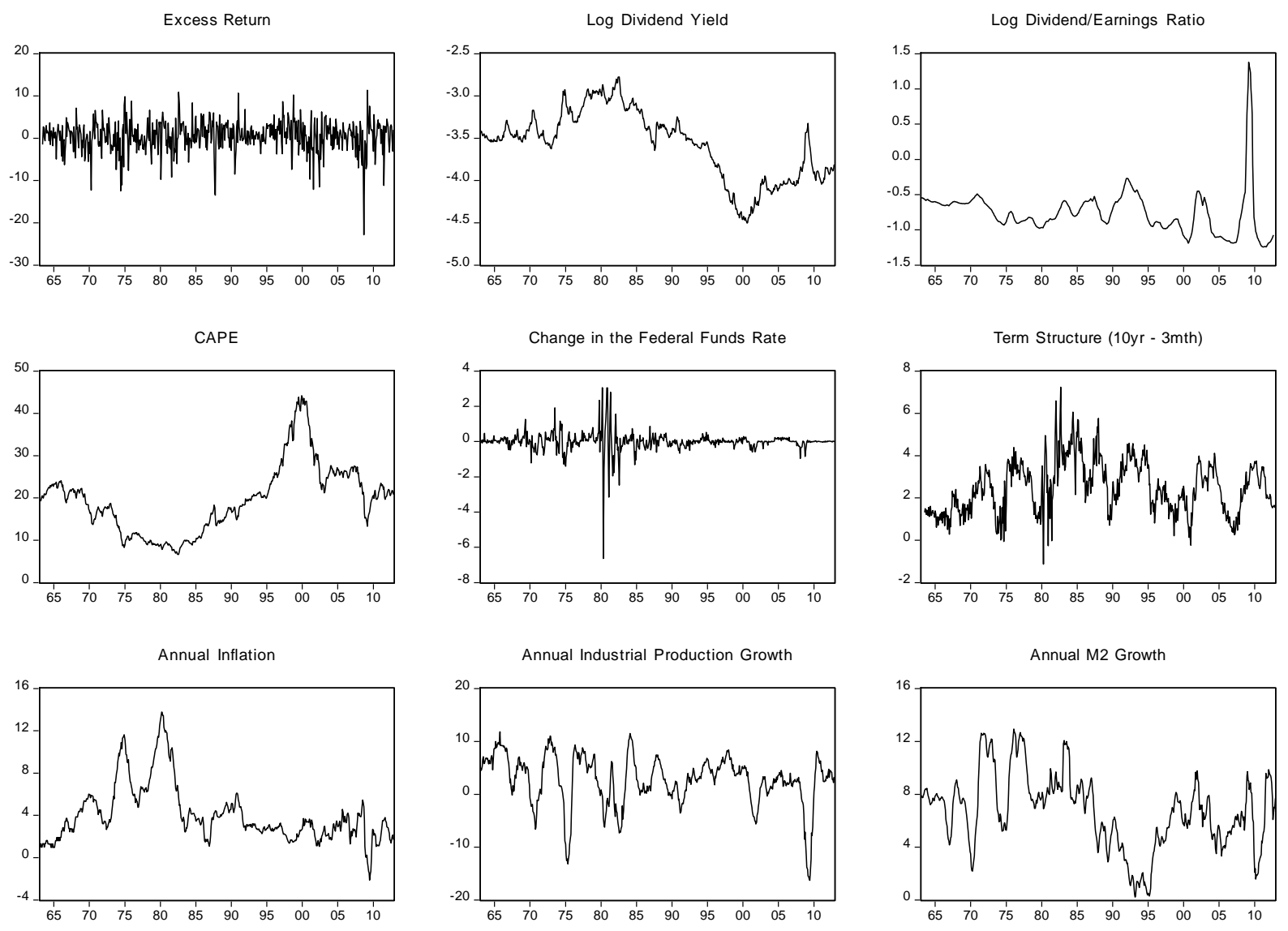